CIUDAD Y TERRITORIO

ESTUDIOS TERRITORIALES

ISSN(P): 2697-231X; ISSN(E): 2697-2328

Vol. LIII, N.․Monográfico 2021

Págs. 83-100

https://doi.org/10.37230/CyTET.2021.M21.05

CC BY-NC-ND

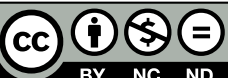

\title{
Embajadores/Lavapiés, ¿un barrio con vulnerabilidad o gentrificado?
}

\author{
Margarita BARAÑANO-CID ${ }^{(1)}$ \\ Pedro UCEDA-NAVAS ${ }^{(2)}$
}

(1)Directora del Departamento de Sociología Aplicada, GRESCO, TRANSOC e Instituto de Investigaciones Feministas, Universidad Complutense de Madrid ${ }^{(2)}$ Dpto de Sociología Aplicada. Universidad Complutense de Madrid. TRANSOC, GISMAT

RESUMEN: A diferencia del análisis de las transformaciones de Embajadores/Lavapiés centrado en la gentrificación, este trabajo persigue evidenciar que dicho proceso coexiste en este espacio con otras dinámicas urbanas, entre las que destaca la producción de distintas modalidades de vulnerabilidad. El trabajo se apoya en la metodología de estudio de caso. Se combina el estudio cuantitativo de la evolución de la vulnerabilidad del barrio, a la luz de la comparación intercensal de 2001 a 2011 y del indicador sintético confeccionado al efecto, de una parte, con el examen cualitativo de los discursos expertos y vecinales, de otra. Como resultado principal, se identifica Embajadores/Lavapiés como un espacio socialmente complejo y heterogéneo, que sigue albergando zonas y colectivos vulnerables, y cuya comprensión requiere tener en cuenta la diversidad de los procesos en curso y sus interrelaciones.

PALABRAS CLAVE: Embajadores/Lavapiés; Barrio; Vulnerabilidad; Gentrificación; Barrio superdiverso.

\section{Embajadores/Lavapiés, A vulnerable or gentrified neighborhood?}

ABSTRACT: Unlike the analysis of the transformations of Embajadores/Lavapiés focused on gentrification, this work aims to show that this process coexists in the same space with other urban dynamics, among which the production of different forms of vulnerability stands out. The work is supported by the case study methodology. The quantitative study of the evolution of the neighborhood's vulnerability is combined -in the light of the intercensal comparison from 2001 to 2011 and the synthetic indicator prepared for this purpose-, on the one hand, with the qualitative examination of experts' and neighborhood's

Recibido: 09.07.2020; Revisado: 13.10.2020.

Correo electrónico: mbaranan@ccee.ucm.es; N. ${ }^{\circ}$ ORCID: http://orcid.org/0000-0002-7733-6907

Correo electrónico: puceda@cps.ucm.es; N. ${ }^{\circ}$ ORCID: http://orcid.org/0000-0001-5734-7564

Los autores agradecen los comentarios y sugerencias realizados por los evaluadores anónimos, que han contribuido a mejorar y enriquecer el manuscrito original. 
discourses, on the other. As a main result, Embajadores/Lavapiés is identified as a socially complex and heterogeneous space, which continues to host vulnerable areas and groups, and whose understanding requires taking into account the diversity of the ongoing processes and their interrelations.

KEYWORDS: Embajadores/Lavapiés; Neighborhood; Vulnerability; Gentrification, Super-diverse Neighborhood.

\section{Introducción ${ }^{1}$}

E n los últimos años han proliferado los estudios sobre el barrio de "Lavapiés", espacio al que en otros estudios se ha hecho referencia como "Embajadores/Lavapiés", combinando la denominación administrativa con el significante más difundido (CASTELLS 1986; GimÉnEZ, 2000; BARAÑANo \& al., 2006; PÉREZAgote \& TEJERINA \& BARAÑANo, 2010; Barañano \& Domínguez, 2015; ÁlvarezBENAVIDES, 2009; ROMERO, 2003, 2006 y 2007; Riesco, 2010; García \& Sequera, 2013; JANOSCHKA \& SEQUERA, 2015; RUIZ ChASco, 2020). La dilatada trayectoria de esta parte de la ciudad, y su protagonismo en los movimientos sociales urbanos que se despliegan en la etapa, primero de la llamada Transición Política, de la mano, sobre todo, de la Asociación de Vecinos La Corrala, que se constituye precisamente en ese período, $y$, más tarde, a partir de múltiples y muy diversas redes, asociaciones e iniciativas vecinales, han coadyuvado, seguramente, a este interés. Pero, sin duda, la profundidad de los cambios registrados en su suelo desde finales del siglo pasado ha jugado un papel decisivo en la conversión del barrio en un referente de su ciudad, a escala nacional e internacional. Si nunca estuvo ausente de la historia de Madrid, o de muchas de las obras literarias o de las composiciones musicales inspiradas en esta misma, su protagonismo en este ámbito, así como en las apreciaciones académicas, e incluso en los medios de comunicación, se acrecienta notablemente a partir de entonces.

\footnotetext{
1 Este artículo es resultado de la confluencia de dos programas de investigación de extensa trayectoria, que, a su vez, se apoyan en distintos proyectos financiados. El primero de ellos, de carácter fundamentalmente cualitativo y de orientación comparada, se basa en los proyectos que se citan en la nota 2 de este artículo. Por lo que hace al segundo, los análisis aquí contenidos prolongan lo recogido al respecto, en primer lugar, en la tesis doctoral de Pedro Uceda, Premio Extraordinario del curso 2015-2016 por la UCM, y titulada "La ciudad desequilibrada"; la segunda fuente de este programa es VUPACI, financiado por la Comunidad de Madrid en el marco de la Convocatoria de 2015 de Ciencias Sociales y Humanidades, dirigida por Marta Domínguez Pérez, en que colaboraron tanto Pedro Uceda Navas, en su condición de PAIT contratado a cargo de la misma, como Margarita Barañano Cid, como investigadora asociada. La
}

Buena parte de los estudios más relevantes sobre este espacio urbano han presentado las transformaciones recientes de Embajadores a la luz, sobre todo, de su gentrificación (GARcía \& SEQUERA, 2013; JANOSCHKA \& SEQUERA, 2015) Otros, han focalizado la atención en su transformación en un barrio de "inmigración" (OBSERVATORIO Metropolitano, 2004), multiétnico o "multicultural" (GIMÉNEZ, 2000; ROMERO, 2003, 2006 y 2007; BaRAÑANo \& Riesco \& Romero \& García, 2006; PÉrez-Agote \&, TEJERINA \& BARAÑANO, eds., 2010; BARAÑANO \& DomíngUEZ, 2015). Una tercera línea de investigación ha centrado la atención en la cuestión securitaria y la importancia de la vigilancia y los dispositivos de seguridad en sus calles y plazas (JANOSCKA \& SEQUERA, 2015; RUIZ CHASCO, 2020). Una cuarta oleada de estudios ha puesto el acento en los procesos que se consolidan en la llamada etapa de poscrisis, esto es, durante la segunda mitad de la última década, muy relacionados también con el impacto de la globalización y con la gobernanza urbana neoliberal de la ciudad, si bien ahora en un nuevo momento de expansión. Entre dichos procesos cabe citar la financiarización de un sector creciente de la vivienda, de la mano de otra vuelta de tuerca de la privatización del mercado inmobiliario, incluyendo la venta a fondos de inversión de parte de la vivienda de promoción oficial en el mismo; la expansión de las viviendas turísticas y de la turistificación, en general, del barrio; la llamada "estudificación"; o, en fin, la expulsión de una parte creciente de sus vecinos hacia una periferia cada vez más lejana.

tercera fuente, en curso, es el programa "Comunidades resilientes. arraigo local y redes sociales en la ciudad global. El caso de Madrid desde un enfoque comparado" (COMURESCM), llevado a cabo en el marco del programa H2019/HUM5738, financiado en la misma convocatoria de la Comunidad de Madrid, a desarrollar entre 2019 y 2023, dirigida por Margarita Barañano Cid, y en el que colaboran tanto Marta Domínguez Pérez como Pedro Uceda Navas. Por último, cabe citar también el proyecto de I+D+i "Influencia de los cambios en los regímenes de producción y acceso a la vivienda sobre la restructuración social de las grandes ciudades españolas" (CSO2017-83968-R), correspondiente al Programa Estatal de Investigación, Desarrollo e Innovación Orientada a los Retos de la Sociedad, convocatoria de 2017, financiado por el Ministerio de Ciencia, Innovación y Universidades. 
La disparidad de consideraciones de que ha sido objeto en la prensa, en la que ha solido estar también muy presente, refleja, además, la diversidad y ambivalencias que rodean a la imagen de este espacio, a caballo entre su enaltecimiento como el "más cool" y "cosmopolita" de Madrid, de un lado, o, de otro, como un "barrio conflictivo" o "inseguro", o incluso un "gueto" en el corazón de la capital. No parece que esta última calificación tenga fundamento alguno, como tampoco cabe pensar que las representaciones rotundamente celebratorias de "Lavapiés" den cumplida cuenta de la heterogeneidad de situaciones que se viven aquí (BARAÑANO \& RIESCO \& Romero \& García, 2006; Pérez-Agote \& TEJERINA \& BARAÑANO, eds., 2010), pero todas ellas resultan expresivas de la atracción que ha llegado a ejercer, y del alcance de la disputa en torno a la apreciación de la misma.

Este trabajo persigue evidenciar que los procesos antes citados no agotan el repertorio de la mudanza de este barrio, y, sobre todo, que conviene alejarse de la consideración de cada uno de ellos por separado, como exclusivo o único eje del cambio en marcha. Precisamente, una de las tesis fundamentales de este artículo es que se trata de un territorio que, aplicando el concepto acuñado por URRY (2004), podemos considerar como socialmente complejo, debido, en buena medida, a la interpenetración de muchas de las dinámicas antes reseñadas, lo que no se debe equiparar con que se trate de un espacio de mezcla social o mixto. $Y$ es que dichas dinámicas, aparentemente contradictorias u opuestas, se despliegan de manera casi simultánea en este tiempo y espacio, amplificando, en muchos casos, sus efectos, como sucede en la etapa aquí analizada con la irrupción de la migración económica extranjera en el barrio, de una parte, y la gentrificación, de otra. La formulación de DONALD (1992), de años atrás, respecto de la centralidad en el mundo urbano contemporáneo de lo que llama las tres " $g$ ", esto es, la gentrificación, la globalización y la guetización, resulta de utilidad para conocer esta realidad que llamamos el barrio de Embajadores, a condición de sustituir el último proceso por el que podríamos denominar como de vulnerabilización, referido, sobre todo, a la des-reconfiguración de nuevas y viejas vulnerabilidades.

Más concretamente, este artículo se centra en esta última dinámica, a veces orillada o relegada, como si se tratara de un rasgo de su pasado o que tendería a declinar en el contexto de su reciente gentrificación. Es más, los restantes procesos comparecerán, pero sólo de manera secundaria, en la medida en que su tratamiento resulte relevante para el objetivo aquí en curso, que es el de comprender la complejidad de este espacio, sobre todo, a través del prisma de sus vulnerabilidades. Precisamente, una segunda tesis de este trabajo es que la vulnerabilidad no sólo ha constituido una seña de identidad de la historia de Embajadores, sino que persiste en el período estudiado, si bien con una incidencia muy distinta según las distintas subzonas y colectivos de este territorio, resignificando sus modalidades anteriores y generando otras nuevas. Una tercera tesis es que esta vulnerabilidad no sólo se entremezcla con los restantes procesos que se despliegan en el período considerado, sino que, además, presenta distintas dimensiones, cuya distinción analítica ayuda a comprender su complejidad, más allá de que, en la realidad, se manifiesten de manera unificada.

Se identifican así, en primer lugar, una vulnerabilidad socio-demográfica, centrada, de un lado, en la irrupción de una población migrante extranjera "superdiversa" (VERTOVEC, 2007) (una parte importante de la cual corresponde con claridad a la migración económica) y en las personas mayores del barrio; en segundo, una vulnerabilidad formativa, expresada en una cierta dualización de los niveles educativos; en tercero, una vulnerabilidad habitacional, y, en un sentido amplio, residencial, vinculada a la existencia de edificios y viviendas en condiciones deficientes y hogares en dificultad.

Hay que añadir que el abordaje en estas páginas de la vulnerabilidad del barrio de Embajadores, como de los restantes procesos, se realiza teniendo en cuenta la triple dimensión del espacio social, cuya distinción analítica permite integrar la consideración no sólo de los aspectos puramente materiales y de los procesos y sociales, sino también del modo en cómo son representados, simbólica e imaginariamente. Esta aproximación, inspirada en la aportación de LEFEBVRE (2013), y en su recepción, entre otros, por SoJA (2006), con su distinción del "espacio percibido", "el vivido" o el "concebido" se aproxima al barrio, y a las dinámicas que tienen lugar en el mismo, como construcciones semiótico-materiales, en las que los discursos y los imaginarios juegan un papel central, además de las dinámicas y las prácticas sociales. En esta dirección, el análisis que sigue de la vulnerabilidad en el barrio, y de cada una de estas dimensiones, no sólo tiene en cuenta la información cuantitativa básica pertinente al respecto sino también el modo en cómo son percibidas representadas e imaginadas, entendiendo que estos últimos aspectos constituyen una parte importante de su constitución. Como en el caso de la conformación de las prácticas y las dinámicas sociales en el barrio, estas dimensiones presentan también una gran complejidad, al tiempo 
que componen un campo de debate, en el que coexisten muy distintas aproximaciones, por lo general, sostenidas por actores sociales diferentes, más que responder a una versión única o unificada. Cabría en esta dirección, referirse a unas representaciones en disputa, muy variables según las percepciones de los distintos colectivos vecinales del barrio, y también conforme a las imágenes y conceptualizaciones de que ha venido siendo objeto, tanto en la literatura sobre el tema como en su construcción por los medios de comunicación. Por último, otra tesis sostenida es que esta vulnerabilidad no puede ser equiparada en absoluto con la de los denominados por RoBERT CASTEL (1997) "espacios de discriminación negativa" sin más, o mucho menos de los espacios de gueto o "hipergueto", según las interpretaciones de estos conceptos de LAPEYRONNIE (2008) y de WACQUANT (2006), categorías de las que estaría muy alejada puesto que muchos de los indicadores producidos, y de los discursos recogidos, apuntan en otra dirección. El impacto en este espacio de la gentrificación, su dinamismo económico y social, la coexistencia de la población "nativa" con la migrante extranjera, o la propia heterogeneidad de esta última, alejaría a Embajadores de ese tipo de periferias "sensibles" (TISSOT, 2013).

\section{Metodología}

El trabajo se apoya en la metodología de estudio de caso, de acuerdo con lo apuntado por Charles RAgin (2014) o Della PoRTA \& KEATING (eds., 2013), en el marco de la cual se lleva a cabo el análisis cuantitativo de la evolución de la vulnerabilidad del barrio, a la luz, sobre todo, del indicador sintético confeccionado al efecto (UCEDA, 2016; VUPACI, 2018), de una

\footnotetext{
${ }^{2}$ La primera investigación a la que hay que referirse, financiada por el Plan Nacional de I+D+i, y dirigida por Fernando García Selgas,se titula "Resignificación de las posiciones de sexo/género y de los hogares en el transnacionalimo 'por abajo'. Estudio de las relaciones sociales transnacionales de los colectivos de migrantes ecuatorianos y senegaleses a partir de sus anclajes en Embajadores (Madrid) y el Campo de Cartagena (Murcia)". En dicha investigación participaron también Carmen Romero, Antonio Agustín García, Celia Vives, Elena Gadea y Margarita Barañano. La investigación se apoya en un trabajo de campo, realizado entre 2008 y 2011, tanto en España (en Madrid, fundamentalmente, en Embajadores, y en Murcia), como en Senegal (Dakar) y Ecuador (Quito, Otavalo y Cañar), e incluye entrevistas en profundidad con personas migrantes, tanto en los múltiples "aquís" como "allís" considerados (34 a personas ecuatorianas y 16 a senegalesas), entrevistas a personas expertas (5), grupos de discusión (5), y observación no participante. También se ha empleado información cualitativa producida en la investigación titulada "Glocalidad e inmigración transnacional. Las relaciones sociales entre grupos étnicos en el espacio metropolitano (Madrid y Bilbao)", dirigida por Alfonso Pérez-Agote, realizada entre
}

parte, y del análisis cualitativo de los desplazamientos de los discursos expertos y vecinales (UCEDA, 2016; BARAÑANO, 2010; BARAÑANO \& al., 2006; ROMERO, 2003, 2206 y 2007; RIESCO, 2010a; Álvarez-BenaVides, 2009 y 2010; PÉREZAgote \& TEJERINA \& BARAÑANO, eds., 2010), de otra. La pertinencia de este enfoque metodológico se fundamenta en la consideración de que el barrio de Embajadores constituye un espacio idóneo para el estudio no sólo de las "nuevas" vulnerabilidades y su conexión con las transformaciones "glocales" contemporáneas sino también para la investigación de su interrelación con procesos como la gentrificación o el impacto de la transnacionalización o la globalización, que son, por otra parte, los que han solido constituir el foco de atención de los estudios más recientes. Además, en la dirección, apuntada por SoJA $(2006,2000)$, se persigue también triangular el análisis espacial con el social y el temporal, abriéndose a la consideración comparada, no sólo en el espacio, sino también en el tiempo, de los procesos a estudio. Así, el análisis espacial tiene en cuenta la comparación del impacto de la vulnerabilidad en el barrio, en el Distrito Centro y en el conjunto de la ciudad, a la vez que se abre a la consideración de distintas subzonas del barrio. El contraste temporal se refiere, sobre todo, a la década que transcurre entre los dos últimos censos de población, esto es, 2001 y 2011, ya que estas dos fuentes sociodemográficas ofrecen los datos básicos requeridos. El estudio cuantitativo llevado a cabo se apoya, además, en diversas investigaciones, finalizadas o en curso, ya citadas. Por lo que hace a la información cualitativa, se recurre, asimismo, a la evidencia empírica obtenida mediante entrevistas y grupos de discusión realizados en el marco de un programa de investigación que abarca ya las dos últimas décadas².

2003 y 2007, coordinada por Benjamín Tejerina, en el análisis de Bilbao y Margarita Barañano, en el de Madrid, y en la que participaron Alberto Riesco, Carmen Romero, Antonio Álvarez, Antonio Agustín García, Beatriz Cavia, Cristina Blanco, Elena Casado, Elsa Santamaría, Fernando García, Gabriel Gatti, Iñaki Martínez y Silvia Rodríguez. El trabajo de campo realizado en Embajadores/Lavapiés de dicha investigación incluyó 6 entrevistas en profundidad a personas migrantes del barrio, 6 entrevistas biográficas, 5 entrevistas a informantes clave de distintas asociaciones del barrio, y cuatro grupos de discusión con personas vecinas del mismo. Hay que citar también citar el proyecto "Globalization, Transnational Immigration and the Restructuring of the Metropolitan Regions of Los Angeles and Madrid: A Comparative Study of Two Communities" (Embajadores and Westlake), llevado a cabo entre 2000 y 2001, coordinado por Margarita Barañano Cid y Raymond Rocco, profesor este ultimo de la Universidad de California, Los Ángeles, que contó con la participación de Carmen Romero, Alberto Riesco o Jorge García López, y con el que se inició esta línea de trabajo. Por último, el Programa VUPACI incluyó también trabajo de campo en Lavapiés. 


\subsection{La unidad espacial}

En el caso concreto que nos ocupa, como se ha señalado, se ha trabajado, sobre todo, con el Censo de Población y Viviendas de los años 2001 y 2011 del Instituto Nacional de Estadística del Estado Español. Esta fuente, única por la minuciosidad de los datos que proporciona en cuanto a desagregación espacial, está limitada por el tamaño y los errores muestrales que produce en cruces de variables a nivel sección censal, siendo esta la mínima unidad espacial de recogida de información. Pero dicha fuente, a pesar de estas limitaciones, es la única que proporciona información más desagregada sobre factores socioeconómicos y residenciales, por lo que resulta la más indicada para los objetivos de este estudio. Con el fin, no obstante, de solventar el problema señalado, se ha llevado a cabo un el tratamiento de la información a través de un agrupamiento de secciones censales, llamadas aquí Unidades Territoriales Agregadas (en adelante, UTA), tal y como se ha venido realizando en otros trabajos y artículos similares



FIG. 1/ Distribución de las áreas espaciales de análisis. Detalle del distrito centro y barrio de Embajadores.

Fuente: VUPACI, 2016. relacionados con el análisis de la vulnerabilidad (UCEDA, 2016; SORANDO \& UCEDA, 2018; UCEDA \& al., 2019; en curso). Cada una de las UTA resultantes tiene un promedio aproximado de 12.000 habitantes, y aúna una media de 7 secciones censales, siendo definidas siguiendo el patrón de morfología urbana de los diferentes municipios que conforman la Región de la Comunidad de Madrid. En el caso del barrio de Embajadores /Lavapiés, dada su densidad de población, las diferentes secciones censales se han agrupado en 4 UTAS (definidas por líneas rojas en la FIG. 1) y las secciones censales en línea de puntos.

\subsection{Análisis cuantitativo}

Tras la definición de la unidad espacial sobre la que se centra el estudio, se aborda el análisis de la medición del proceso de vulnerabilización teniendo en cuenta su carácter y composición multifactorial. Los estudios acerca de los procesos de vulnerabilidad han sido numerosos en los últimos tiempos y abarcan diferentes ámbitos como el urbanismo (HERNÁNDEZ, 2007; TEMES, 2014), la geografía (MENDEZ \& ABAD \& ECHAVES, 2015) o la sociología (UCEDA, 2016; Antón-Alonso \& al., 2017; Antón-Alonso \& PORCEL, 2018; FERNÁNDEZ-GARCÍA \& al., 2018; DOMÍNGUEZ \& SORANDO \& UCEDA, 2019).

Con la idea de trabajar de manera multisectorial, siguiendo la línea de los trabajos citados, el proceso de vulnerabilización, se ha tratado de definir dimensiones equiparables en los datos de 2001 y 2011 que posibiliten, en la medida de lo posible, el entendimiento de su evolución y la comparación temporal. Como se ha mencionado al principio de este capítulo, la vulnerabilidad no es un fenómeno unidimensional, diferenciando para nuestro análisis los siguientes aspectos:

- La dimensión demográfica hace referencia básicamente, a la población dependiente, de un lado, tanto de la llamada tercera como de la cuarta edad, o de los jóvenes menores de 16 años, así como de los colectivos de personas migrantes económicas extranjeras.

- La dimensión laboral trata de explicar las desigualdades en términos de cualificación del trabajo desempeñado o la estabilidad laboral según la duración del contrato de trabajo.

- La dimensión formativa, muy relacionada con la anterior, muestra la importancia del nivel académico de la población. 
- La dimensión habitacional, residencial y de los hogares, ya que suele existir una relación estrecha entre la población en situación de riesgo de sufrir vulnerabilidad y unas malas condiciones habitacionales.

Por lo que hace al análisis cuantitativo de la vulnerabilidad en Embajadores, se ha adoptado una metodología basada en la elaboración de indicadores sintéticos que posicionen las unidades de análisis en relación con el resto del distrito o del municipio de Madrid, método ya aplicado en la literatura sociológica, y desde el urbanismo, al caso de Madrid (ALGUACIL, 2006) o, de manera más amplia, al Estado Español (Alguacil \& CAMACHo \& HERnÁNDEZ, 2013). Más concretamente, el estudio cuantitativo de los procesos de vulnerabilidad se complementa con el análisis realizado de acuerdo con la metodología definida por TEMES $(2014)^{3}$ para el municipio de Madrid con datos del Censo de Población y Viviendas de 2011, utilizando como unidad de análisis espacial las UTAS ya definidas. Conscientes de la limitación que tienen las bases de datos que se manejan para ilustrar las diferentes aristas de la vulnerabilidad, la metodología propuesta consiste en la reducción de las dimensiones mediante el análisis de componentes principales (ACP) de cada una de las que se definen en este apartado para estudiar los procesos de vulnerabilización. Una vez definidas las dimensiones de la vulnerabilidad a estudiar, la identificación de una unidad espacial de análisis como "vulnerable" se realiza a través de la posición que obtiene y su comparación mediante desviaciones estándar-con respecto a la media del resto del municipio. Más concretamente, el modelo de análisis seguido se ha centrado en tres tipos de dimensiones básicas: las referidas a la existencia de colectivos en riesgo de sufrir vulnerabilidad urbana de acuerdo con la composición sociodemográfica de la población residente, distinguiendo aquí la referida a la edad y al tipo de hogar, de una parte, $\mathrm{y}$, de otra, al origen nacional, de acuerdo con la procedencia o no de países ajenos a la UE o la OCDE, que definiría a las personas migrantes económicas extranjeras; las relativas al peso de diferentes variables de corte educativo y laboral; y las referidas al entorno residencial o la modalidad habitacional.

\section{Resultados. Dimensiones de la vulnerabilidad de Embajadores/ Lavapiés: sociodemográfica, educativa, laboral, habitacional y residencial}

Si bien en los últimos años Embajadores ha sido analizado, sobre todo, a la luz de su gentrificación, o, en otros casos, refiriéndose a su protagonismo como barrio multiétnico o multicultural, lo cierto es que no sólo presenta importantes vulnerabilidades, sino que, además, muchas de ellas enlazan con una larga historia anterior, aunque casi todas ellas se resignifican en el nuevo contexto metropolitano y transnacional. Algo, además, que afecta tanto a los procesos sociales previos desplegados en su suelo como a los discursos, representaciones e imágenes referidos al mismo, en todos los cuales están presentes diferentes aspectos de la vulnerabilidad. Así, esta larga trayectoria previa se reflejó, inicialmente, en su condición de espacio de arrabal fuera de las murallas; luego, en su identificación como "barrio bajo", destinado a artesanos y actividades comerciales; desde la mitad de siglo XIX, se reconfigura, asimismo, como un espacio de clase obrera, habitado por personas trabajadoras de las fábricas cercanas (La Tabacalera, y otras en Arganzuela, etc.), todo lo cual se combina, ya tempranamente, con su identidad como el barrio "tradicional y castizo por excelencia de Madrid, a la que se suma posteriormente la de "barrio republicano" durante la Guerra civil española y posteriormente. El contraste entre el protagonismo de Embajadores, y, sobre todo, del espacio de Lavapiés, en la memoria de la ciudad, de un lado, y la profundidad de sus precariedades, de otra, constituye una expresión más de la complejidad y múltiples ambivalencias que rodean a este barrio histórico, presentes tanto en el terreno de las representaciones como en el de las prácticas y procesos sociales.

Es importante destacar que no fue un espacio decisivamente afectado por el "éxodo rural" de mediados de los años 50 a mediados de los 70, y que pierde población, entre otros períodos, desde la década los setenta hasta la segunda parte de los años noventa del siglo pasado, esto

\footnotetext{
${ }^{3}$ Esta metodología se basa en la reducción de dimensiones a través de análisis de componentes principales, con la intención de establecer indicadores sintéticos que delimiten el posicionamiento de cada una de las unidades espaciales en relación a esta medida. Un espacio vulnerable se define por la situación con respecto a la media del municipio, considerado en desviaciones estándar. Temes considera cuatro
}

factores sociales en su análisis: el envejecimiento, la integración social, la inmigración y la dimensión residencial. No obstante, el autor emplea diversas fuentes de datos ajenas al Censo de Población y Viviendas, por lo que los indicadores empleados para definirlos son diferentes al modelo aquí expuesto. Para más información, TEMEs (2014). 
es, durante la etapa inmediatamente anterior a la del inicio de la oleada grandes cambios en su suelo, vinculados, entre otros aspectos, a la irrupción de una población migrante extranjera transnacional desde el final de los años 90s del siglo $\mathrm{XX}, \mathrm{y}$, especialmente, desde el comienzo de este siglo. A ello se va a sumar, como se ha señalado, una gentrificación ascendente a partir prácticamente de estas mismas fechas, así como distintas intervenciones administrativas, de diferente signo, y otros procesos más recientes, muchos de ellos relacionados con la reestructuración posterior a la crisis de 2008. Entre estos cabe citar la turistificación, que ha supuesto un importante impacto de las viviendas turísticas o la atracción de personas residentes extranjeras de perfiles muy distintos, al proceder de países europeos o de la OCDE y estar involucradas en movilidades educativas 0 profesionales. En el marco de todas estas dinámicas se refuerzan algunas de las vulnerabilidades "heredadas" y se configuran otras nuevas, que se analizan en lo que sigue.

Cabe constatar, en primer lugar, un reforzamiento de su condición de barrio densamente poblado con 437,8 habitantes por ha., muy por encima de las 257,9 personas por $\mathrm{Ha}$. del distrito Centro, en el que se engloba. La escasez de zonas verdes, el predominio de calles que responden al patrón de un casco histórico, o las nuevas modalidades de hacinamiento, vinculadas, sobre todo, entre 2001 y 2011 , a la llegada de personas extranjeras migrantes económicas, que encuentran en el barrio la posibilidad de satisfacer sus demandas urgentes de alojamiento, al menos, en un primer momento, contribuyen a este resultado. La referencia a un barrio que "no transpira" (PÉREZ AgOTE \& TEJERINA \& Barañano, eds., 2010), expresada por alguno de sus habitantes, enlaza también este rasgo con una vulnerabilidad medioambiental y urbanística que persiste. Lo contrario sucede en lo que se refiere a su decrecimiento poblacional, registrado hasta mediados de los noventa del siglo pasado, y que va a ser sustituido por una importante recuperación demográfica. Esta se vincula, en cierta medida, a la atracción de una población adulta que, en muchos casos, encaja en el perfil de los sectores sociales de las llamadas nuevas clases medias funcionales, que suelen estar más implicados en las primeras fases de la gentrificación urbana, compuestos por profesionales, profesores o artistas, entre otros. Los nuevos "vecinos" de sectores medios, como muchos de los numerosos transeúntes, se van a ver atraídos por las posibilidades de ocio y consumo en este espacio, por su centralidad y buenas comunicaciones, por los precios todavía algo menores de su mercado inmobiliario, por comparación con otros distritos del Ensanche, y por su imagen de "barrio de toda la vida" (PÉrez Agote \& TEJerina \& Barañano, eds., 2010). Es interesante que su conversión en uno de los entornos multiétnicos o multiculturales más conocidos de la ciudad va a constituir también un factor de interés para esta población (BARAÑANO \& al., 2006; ROMERO, 2003, 2006 y 2007; PÉREZ Agote \& TEJERINA \& Barañano, eds., 2010; RIESCo, 2010a y 2010b; ROMERo, 2006 y 2010, BENAVIDES, 2009 y 2010), que busca "consumir" el exotismo y aparente cosmopolitismo derivados de su transnacionalización creciente (BARAÑANO, \& al., 2006; PÉREZ Agote \& TEJERINA \& BARAÑANo, eds., 2010; Riesco, 2010; RoMERo, 2003, 2006, 2007 y 2010; BEnAVIDES, 2009), poniendo de manifiesto el reforzamiento de estas dinámicas, aparentemente contradictorias y hasta opuestas. Algo que sucede también con este último proceso y el fortalecimiento de su protagonismo como espacio movilizado, relacionado, a su vez, con la numerosa presencia en su suelo de personas vinculadas a movimientos sociales y a un discurso comunitarista orientado a "hacer barrio".

A los componentes nacionales de esta nueva población se le va a añadir, a partir de este siglo, y, sobre todo, de la etapa de recuperación posterior a la pasada crisis económica, nuevos vecinos procedentes de la Unión Europea o de países de la OCDE. Entretanto, la principal fuente del incremento poblacional en el período intercensal de 2001 a 2011 es, sin duda, la recepción de una población migrante extranjera, por razones económicas, casi previamente desconocida con anterioridad en Embajadores. Dicha población llega a suponer un $35,16 \%$ del total poblacional de este espacio en 2006, y se reduce algo a partir de este año, anticipándose a la crisis de 2008 , como consecuencia del encarecimiento del mercado inmobiliario, sobre todo, de los alquileres, y del desplazamiento de parte de estos nuevos habitantes hacia los distritos del Sureste madrileño. Como resultado de estos cambios, el porcentaje de personas migrantes extranjeras se aminora hasta el $24 \%$ por ciento de 2011 , pero seguirá alcanzando un peso muy superior a otras zonas de la ciudad y a los restantes barrios del Distrito Centro, configurando una de las nuevas vulnerabilidades del mismo, debido a las peores condiciones residenciales, laborales o educativas que presenta en este momento esta nueva población.

Una mujer senegalesa, que trabaja en un restaurante propio en Lavapiés, lo expone con bastante claridad en un grupo discusión realizado en el marco de la investigación, ya citada, titulada "Glocalidad e Inmigración Transnacional. Las relaciones sociales entre grupos étnicos en 
el espacio metropolitano (Madrid y Bilbao)", dirigida por Alfonso Pérez-Agote, y cuyos resultados se recogen, entre otros textos, en PÉREZ Agote \& TEJERINA \& BARAÑANO (eds., 2010):

"Coges una calle hay un chino, el otro un árabe, das la vuelta y un negro al lado, Bangladesh, India. Aquí está la concentración de todos los inmigrantes que quieras encontrar en España, estamos aquí" (grupo de discusión de mujeres procedentes de países de mayoría islámica, coordinado por Carmen Romero en 2005).

Las características locales específicas de Embajadores/Lavapiés, combinadas con el impacto global que se produce a mediados de la última década del siglo pasado, inciden, de forma importante, en esta recepción de inmigrantes transnacionales. Entre ellas, cabe citar múltiples fortalezas, y también vulnerabilidades previas, como su centralidad urbana y óptimas comunicaciones, que facilitan el desplazamiento hacia otras partes de la ciudad, aun careciendo de vehículo privado; la existencia de un amplio mercado de infravivienda o de alojamientos en malas condiciones, así como la constitución de un mercado irregular de alquiler al alcance de los inmigrantes; la posibilidad por ello de reforzar el hacinamiento habitacional, característico de la historia de este barrio, con fenómenos como las "camas calientes" o los llamados "pisos patera" en los años en que irrumpe este nuevo flujo migratorio; la presencia de redes de apoyo e intercambio compuestas por las comunidades de inmigrantes previamente asentadas en el barrio; la expansión de enclaves y economías étnicas en su suelo, todavía en vigor; o en fin, las representaciones imaginarias de muchos de sus nuevos colectivos, que perciben Embajadores/Lavapiés como un espacio "seguro" o "cercano", incluso como un "refugio", debido a la presencia de otras personas de idéntica nacionalidad, o procedentes del mismo Continente (PÉREZ Agote, TEJERINA \& Barañano, EdS, 2010; García SElgas, 2016). Todo ello jugó a favor de la conversión de este espacio en una suerte de "pista de aterrizaje" para múltiples personas migrantes, que encontraron en el mismo una solución a sus urgentes necesidades de alojamiento, en la mayor parte de los casos, altamente precaria, pero rápida y viable.

Un mediador vecinal, habitante del barrio en años previos, de 40 años entonces, entrevistado en 2006, resume la historia y situación del barrio de la siguiente manera:

"Era un barrio diferente, era un barrio obrero (...) de personas de baja cualificación que vivían hacinadas y bajos recursos económicos, que convivía mucho en el ambiente de corrala, eran familias, que en ese momento había de todo, jóvenes y viejos, de varias edades, y había un chabolismo vertical, como ahora, quizás menos deteriorado... (...) cuando el inmigrante llega aquí (...) es el único sitio donde se alquila masivamente a población inmigrante (...) Sigue siendo Lavapiés, donde hay una infinidad de infravivienda y de situación de oferta".

Por su parte, una mujer ecuatoriana, en una historia de vida realizada en 2011 describe el paso por diferentes viviendas, donde fueron alquilando habitaciones, nunca una vivienda completa, primero, por parte de su marido, que estuvo en la casa de unos conocidos, a quien luego se sumaron ella y sus dos hijas:

\footnotetext{
"entonces después ya buscó una habitación, cuando nosotras llegamos él estaba en una habitación, entonces tuvimos que vivir ahí unos seis meses (...) terrible vivir con las niñas en una habitación (...) Yo lloraba porque vivir en un piso pequeñito con las niñas, yo es que me quería regresar (...). Los cuatro en una habitación, teníamos una litera, las niñas arriba y luego abajo nosotros, después en el mismo edificio me encontré un piso más pequeño".
}

El notable y casi continuo crecimiento del vecindario vinculado a la gentrificación, si bien se acompaña de dinámicas de recuperación económica y social, como las derivadas del crecimiento poblacional y el rejuvenecimiento etario, aminorando así dos aspectos de la vulnerabilidad muy presentes en el pasado inmediato del barrio, acaba relacionándose, sin embargo, de otra, con nuevas vulnerabilidades, al tiempo que refuerza algunas de las anteriores. Entre ellas cabe mencionar las relativas a la subida de precios y las expulsiones tanto de distintos colectivos poblaciones como de parte del comercio tradicional y local, lo que enlaza con la espiral de las rehabilitaciones y expulsiones de los años setenta del siglo XX (CASTELLS, 1986) y que, precisamente, constituyó el eje temático principal del movimiento social urbano en Embajadores en esa etapa, incluyendo las actividades de la entonces constituida Asociación de Vecinos de La Corrala. En años recientes, el nuevo incremento de los alquileres, de los pisos turísticos y de los nuevos negocios vinculados a las demandas de la turistificación, o de los sectores profesionales instalados en el barrio, van a reforzar de manera significativa estas tendencias.

Buena parte de las nuevas vulnerabilidades en Embajadores se ven incrementadas, asimismo, por el cambio sociodemográfico expuesto, especialmente, por la incorporación de personas migrantes extranjeras venidas a España 


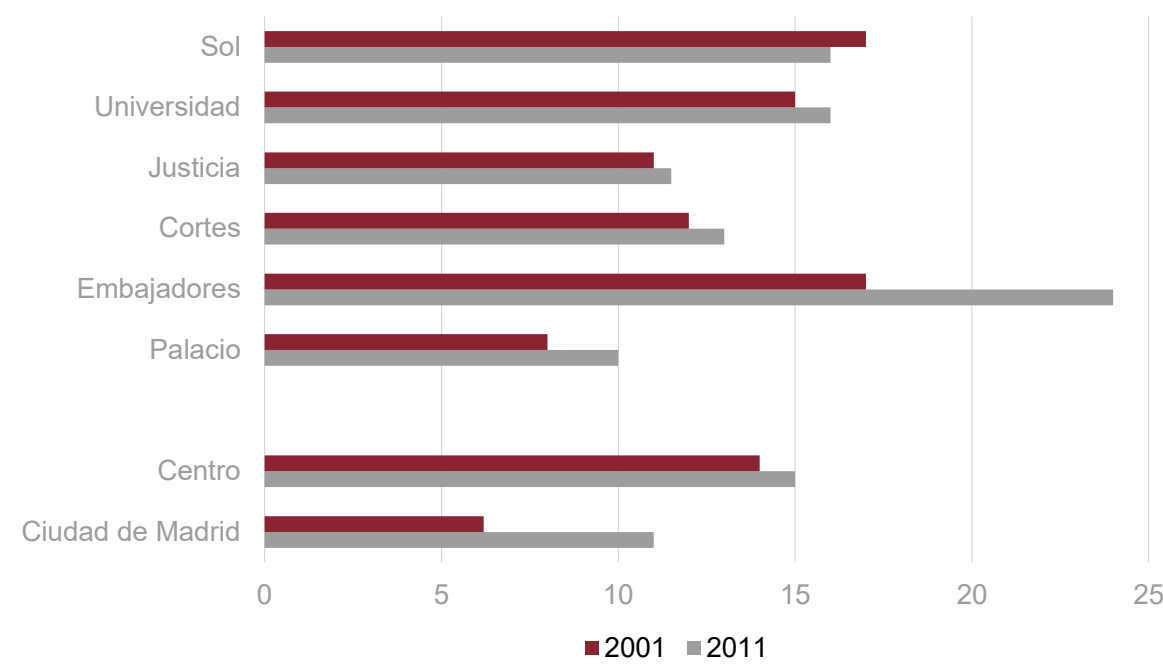

25

FIG. 2/ Porcentaje de población inmigrante económica (No EU ni América del Norte).

Fuente: elaboración propia a partir del Censos de población y viviendas (INE).



Fuente: Censos Población y viviendas 2001 y 2011.

fundamentalmente por razones socioeconómicas, y desde países de fuera de la OCDE o de la UE. Y ello es así porque una parte significativa de estas personas afrontan, en ese momento, unas condiciones habitacionales, residenciales, educativas y laborales más precarias que otros colectivos del barrio, especialmente, que el contingente "gentrificado" del mismo, o de quienes residen otros barrios del Distrito Centro de Madrid.
Así, por lo que hace a la dimensión educativa de la vulnerabilidad, la comparación intercensal pone de manifiesto que, si el barrio de Embajadores contaba ya en 2001 con el porcentaje más elevado de personas con estudios primarios (FIG. 3), situándose muy por encima del conjunto del Distrito, siendo superior incluso al del total de la ciudad, la llegada de este nuevo flujo migratorio fortalecerá esta desfavorable situación, y de manera significativa. $Y$ es que el 
citado porcentaje pasa de $13 \%$ en 2001 a cerca del $18 \%$ en 2011 , aumentando casi 5 puntos en estos diez años. Este aumento de los niveles educativos inferiores se produce, no obstante, a la vez que el de los superiores, como se recoge en la FIG. 3, lo que evidencia la heterogeneidad de las nuevas personas vecinas incorporadas al barrio en la etapa intercensal, así como la relativa dualización de los procesos en curso. Estos datos no parecen poner tanto de manifiesto una tendencia a la homogeneización de la población del barrio, o a su mezcla social, sino, por el contrario, apuntan la coexistencia de procesos muy distintos, como la gentrificación, la vulnerabilización o la transnacionalización, que, sin embargo, se interrelacionarían, contribuyendo a reforzar viejas vulnerabilidades y a confirmar otras nuevas.

El análisis de algunos datos laborales básicos señala, igualmente, la importancia de la precariedad laboral entre las personas del barrio, al menos si lo comparamos con la que arrojan los datos de otros espacios del Distrito Centro. Es cierto, no obstante, que en este caso no se produce un empeoramiento de las cifras entre 2001 y 2011, sino una cierta mejoría. Por lo que hace al impacto del trabajo temporal, en la figura 4 se recoge que Embajadores/Lavapiés arroja los datos más negativos del Distrito, así como una reducción relativa de este indicador inferior a la que acontece en otros barrios del mismo. Si se considera la tasa de paro, la comparación intercensal, expuesta en la FIG. 4, ratifica la leve mejoría producida entre 20011 y 2001, pese al impacto de la crisis económica, si bien Embajadores muestra los datos más adversos del conjunto del Distrito, siendo también más desfavorables que los de la ciudad de Madrid. Conviene destacar también que, si el barrio muestra indicadores muy distintos a otras partes de Centro, tampoco es homogéneo internamente, ni sucede, como se ha mencionado, que unos colectivos y otros se mezclen en su territorio. Por el contrario, diferentes estudios han venido poniendo de manifiesto la existencia de una fuerte segregación espacial interna de Embajadores, tanto por lo que hace a sus distintas subzonas como a los edificios que lo ocupan, entre los que, en algunos casos, existen fuertes diferencias, en cuanto a su estado de conservación, personas que lo habitan o características de sus viviendas. Concretamente, por lo que hace a las personas migrantes extranjeras procedentes de países ajenos a la UE o a la OCDE, se ha constado por distintas investigaciones, y para diferentes períodos, que su peso resulta más elevado en el interior del barrio, esto es, alrededor de la Plaza de Lavapiés, donde es mayor también la precariedad habitacional, residencial y medioambiental. Resulta menor, por el contrario, en el extremo Norte del barrio, donde representa casi la mitad que en la anterior; en parte del Rastro, entre las calles Ribera de Curtidores y Toledo; y alrededor del Bulevar de Argumosa, esto es, en las zonas

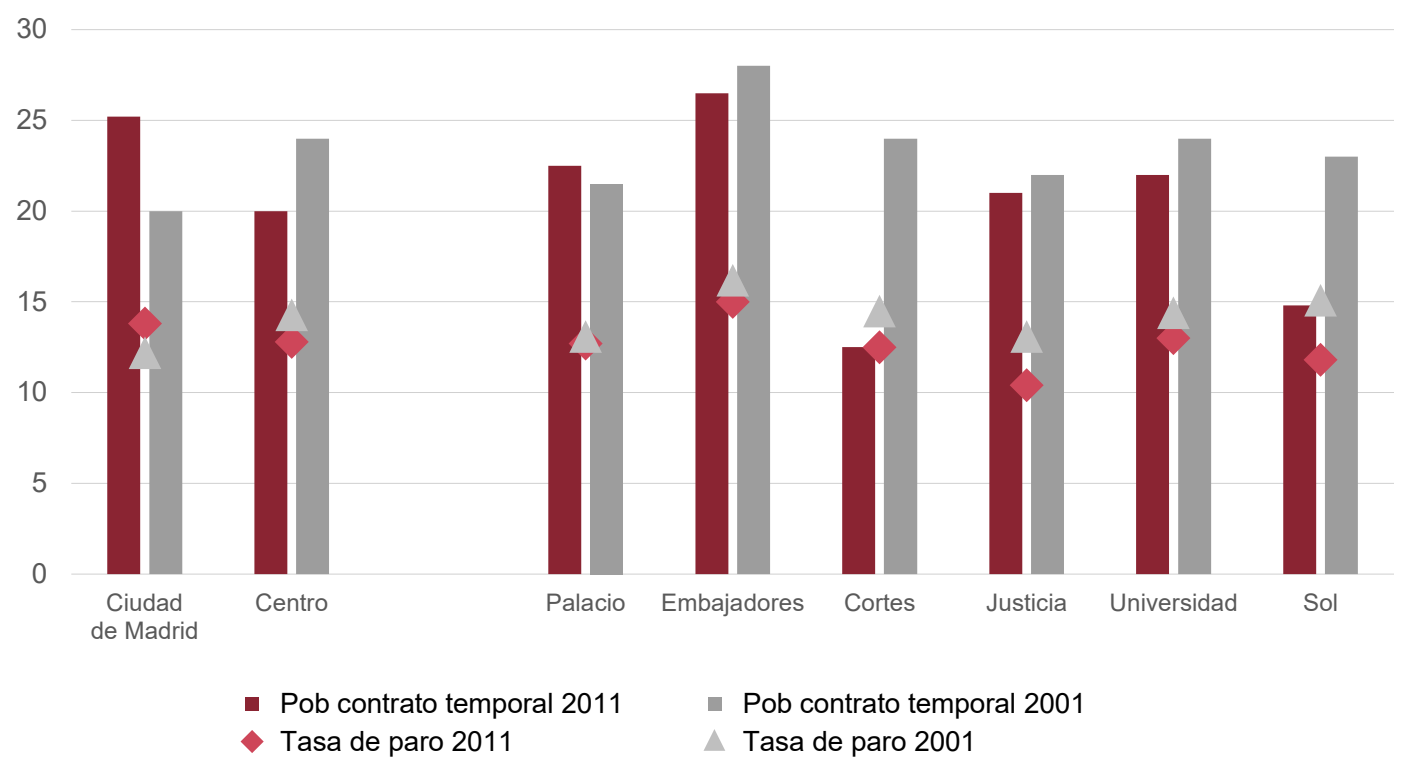

FIG. 4/ Porcentaje de población con contrato temporal y tasa de paro, 2001-2011.

Fuente: Censos Población y viviendas 2001 y 2011. 
Oeste y Este del barrio, incluyendo los bordes del mismo, por lo general más gentrificados, sobre todo, por lo que hace a los del Sur y el Este, en los que tienen su sede equipamientos culturales estratégicos.

En definitiva, la subzona interior de Embajadores, con más migrantes extranjeros, es también aquella en la que se concentra el mayor número de comercios "étnicos", de edificios en mal estado, de infraviviendas y de viviendas en alquiler. También se supone que es donde ha estado más presente el mercado informal de alquiler, y el hacinamiento. (FIG. 5) El análisis del espacio denominado como Lavapiés, que engloba tres UTAS de las cuatro que conforman el barrio de Embajadores, debido a su densidad poblacional, especialmente elevada, demuestra que, además de la presencia en su suelo de nuevos colectivos con una mejor cualificación tanto académica como profesional, tiene, asimismo, un peso destacable la población extranjera precarizada que habita, por lo general, viviendas de alquiler junto con la presencia, en menores términos, de población adulta mayor con la vivienda totalmente pagada. En conjunto, Embajadores/Lavapiés ha venido asistiendo

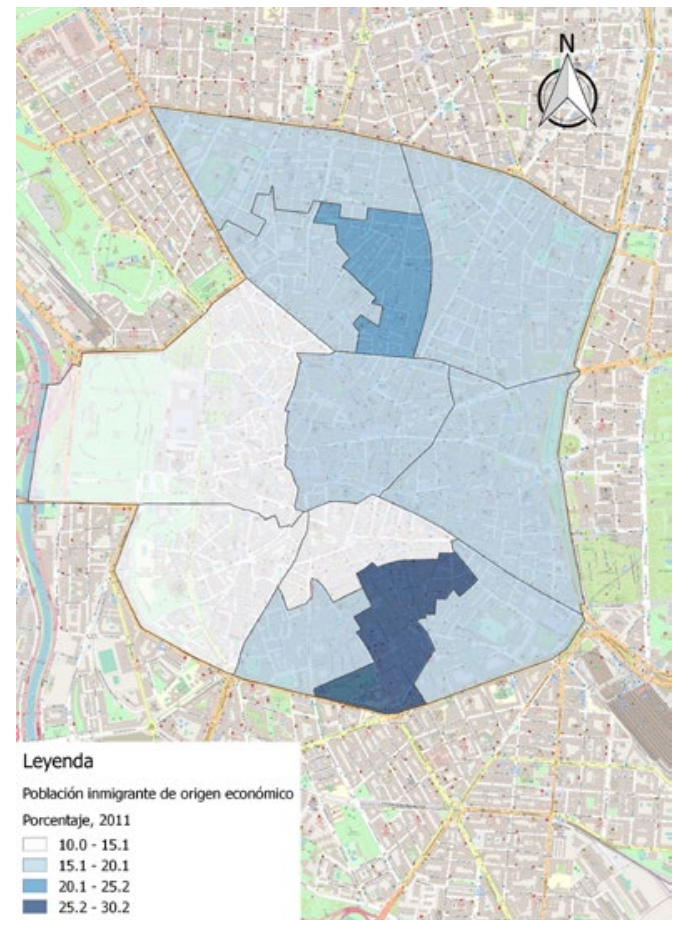

FIG. 5/ Distribución de la población inmigrante dentro del Barrio de Embajadores según zonas espaciales.

Fuente: elaboración propia a partir de Censos de población y viviendas (INE) desde 2001, a un progresivo rejuvenecimiento poblacional, lo que contrasta con su larga historia como espacio particularmente envejecido, como era el caso también de otros del Distrito Centro.

Como consecuencia de la atracción de personas adultas, potencialmente activas, bien sea debido a la gentrificación, de un lado, o al impacto en el barrio de los nuevos flujos globales de migración transnacional, de otro, se produce una concentración significativa de la población en las edades centrales.

El análisis estadístico confirma esta evolución, poniendo de manifiesto, igualmente, la reducción del peso de la infancia (0-14 años) y de la juventud (15-29 años) en el barrio. Esta reducción de las personas jóvenes (FIG. 6), que contrasta con su alta visibilidad en las calles y negocios del barrio, y su participación en muchas de sus actividades, sobre todo, de las vinculadas a la movilización social, evidencia la gran capacidad de atracción de transeúntes de Embajadores, su intensa relación con otras partes de la ciudad, y a la vez, la imposibilidad creciente de esta población joven, sobre todo, en la franja etaria superior, para residir en el mismo, debido al incremento de sus precios.

Esta fuerte comunicación con otras partes de la ciudad aleja, además, a este espacio, definitivamente, de la noción de espacio de discriminación negativa (CASTEL, 1997), de gueto (LAPEYRONNIE, 2008; ESEVERRI, 2017) o de hipergueto (WACQUANT, 2007), uno de cuyos rasgos definitorios compartido es, precisamente, su relativo aislamiento respecto de otras áreas urbanas y su escasa atracción de personas o de actividades económicas o sociales de fuera del barrio.

Ahora bien, pese a la reducción de las personas mayores de 65 años, aún subsiste en este barrio un contingente significativo, y a veces olvidado, de personas de más de 75 años, de lo que se ha llamado una cuarta edad, que, en muchos casos, sufren una importante vulnerabilidad. Ello se debe a que este colectivo está compuesto, en su gran mayoría, por mujeres mayores que viven solas (22,6\% del total de hogares en 2011$)$ con frecuencia, en edificios sin ascensor y otros medios de accesibilidad, y que, en consecuencia, están atrapadas en sus viviendas. Estas, en algunos casos, carecen de servicios básicos como la calefacción u otros, como también suele ocurrir que los medios económicos de estas personas son más reducidos, por disponer de pensiones menores. Esta población de cuarta edad habita, sobre todo, en la parte Oeste del barrio, como se observa en la FIG. 7, en la que el porcentaje de personas adultas 




FIG. 6/ Población infantil y joven según grupos de edad, barrio Embajadores / Lavapiés.

Fuente: Padrón continuo de habitantes (INE).

migrantes extranjeras es más bajo. Es también la misma subzona en la que hay más viviendas con alguna deficiencia, como se muestra en el estudio de las vulnerabilidades (FIGS. 8 y 9 ).

La vulnerabilidad sociodemográfica se interrelaciona así estrechamente con la habitacional, residencial y urbanística, todas las cuales tienen una larga historia en Embajadores/Lavapiés. Conviene recordar, en esta dirección, lo apuntado por Castells (1986) respecto de la movilización de Embajadores, en la obra en la que analiza algunos de los movimientos sociales urbanos de Embajadores, que cita como emblemáticos de esa etapa. $Y$, como expone, el eje de dicha movilización, y de la creación de la Asociación de Vecinos La Corrala, fue precisamente el problema de la vivienda y el rechazo a las expulsiones de los vecinos del barrio, debido a la declaración de ruinas de múltiples edificios. Frente a las actuaciones que conducían al abandono forzado del barrio por parte de su vecindario, desde la Asociación de Vecinos de la Corrala se defiende entonces la "rehabilitación sin elitización", así como el compromiso de ofrecer, en los casos extremos, vivienda en el barrio a quienes se pudieran ver afectados por dichas expulsiones. Otro objetivo de la protesta que protagoniza Embajadores en esa etapa es revertir los planes de demolición de parte de sus edificios, algunos de ellos icónicos, como la conocida corrala situada entre la calle Sombrerete y Mesón de Paredes.

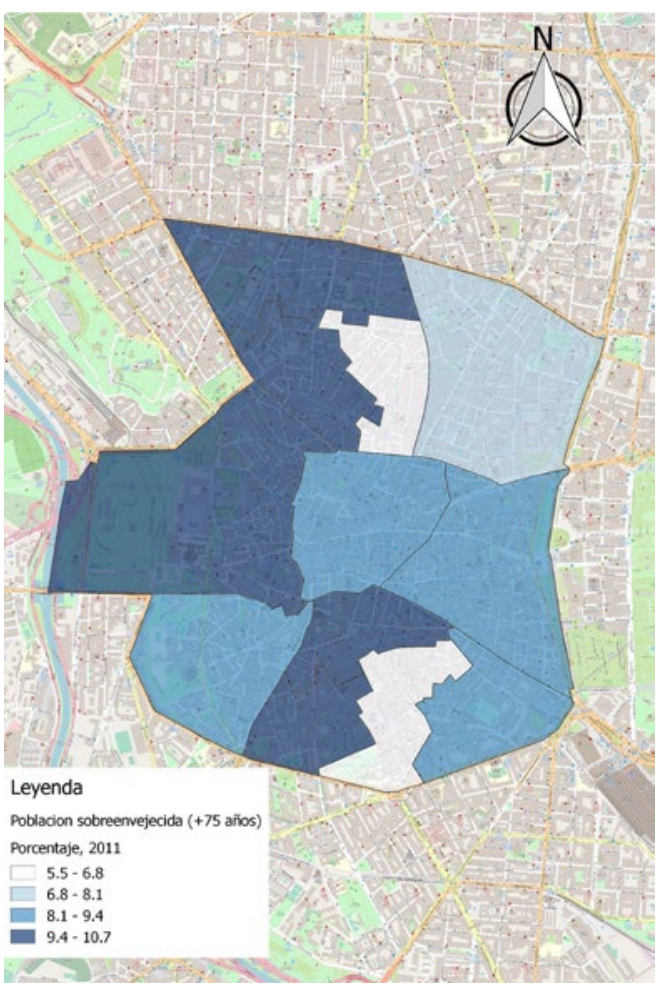

FIG. 7 / Distribución de la población de cuarta edad (+75 años), 2011.

Fuente: elaboración propia a partir de los datos del Censo de población y viviendas 2011. 
Por último, otro aspecto central que se tematiza en ese momento es el de la infravivienda y el llamado chabolismo vertical, esto es, las pésimas condiciones de algunos de los alojamientos, sobre todo, por lo que hace a la carencia de accesibilidad, de servicios básicos y a las reducidas dimensiones de los mismos, que contrasta aún con un tamaño medio de los hogares elevado.

El presidente de la Asociación de Vecinos de La Corrala lo expone del siguiente modo en una entrevista realizada en 2006:

“(...) la mayoría de los que están viviendo en infravivienda son de dos tipos, el autóctono chaval joven, chavala joven, que viene a vivir aquí (...) e infravivienda donde viven un montón de inmigrantes (...) también hay viviendas de 60, 70 metros cuadros, en el cual el comedor desaparece, se convierte en una habitación más (...) son familias enteras que se cogen una habitación y viven en una habitación ...). También es verdad que no suelen estar mucho tiempo, porque el primer sitio donde suelen venir es al centro, porque les pilla más cerca moverse porque estás en el centro de Madrid, luego si encuentra trabajo en otro lado suele irse a vivir a otro lado, es decir, que aquí el inmigrante no suele quedarse mucho tiempo".

Otra cuestión que enlaza directamente las vulnerabilidades conocidas en la historia de Embajadores con las conformadas en el período intercensal analizado es el relativo al hacinamiento como recurso de acceso al alojamiento, relacionado tanto con el tamaño insatisfactorio de muchas de las viviendas como con el fenómeno del subarriendo de los espacios interiores de las mismas, sobre todo, de las habitaciones. Se trata de un fenómeno expresivo de la condición popular y luego obrera de un barrio que se configura, ya tempranamente, como un espacio de acogida de los sectores populares, incluso, de los venidos a la capital, ya en siglos previos, empujados por la necesidad económica. Entre 2001 y 2011, la población migrante extranjera venida también por razones fundamentalmente económicas, reedita esta vieja vulnerabilidad del barrio, si bien resignificada en el nuevo contexto global, que hace que coexistan personas procedentes casi de más de ochenta nacionalidades de origen diferentes. La conformación de un mercado del alquiler informal, accesible incluso a personas "sin papeles", y la urgencia de satisfacer la necesidad de alojamiento, va a derivar en la extensión en ese momento de cohabitaciones o subarriendos en condiciones de hacinamiento (LEAL \& MAYEUR, 1997; LEAL \& ALGUACIL, 2012; MARTínEZ \& LEAL, 2008). EI subarriendo en ese período, y en la etapa inmediata de llegada, se refiere bien a una habitación o a un sofá, una "pileta" o un sillón, o bien al alquiler de una cama durante unas horas, reviviendo el fenómeno de las llamadas "camas calientes" (BARAÑANO \& al., 2006; ROMERO, 2003, 2006 y 2007; PÉrez-Agote \& TEJERINA \& BARAÑANO, eds., 2010; GARcía Selgas, 2016). Se trata, sin duda, del aspecto más destacado, junto con la dificultad de acceso a la vivienda, por la subida de precios, que aparece en los relatos y representaciones de las personas y grupos entrevistados en ese período, como pusieron entonces de manifiesto las investigaciones llevadas a cabo. Lo que, por cierto, evidencia también la pertinencia de combinar al respecto el análisis cuantitativo y el cualitativo, debido a que muchos de estos procesos permanecen en buena medida impermeables a las fuentes estadísticas oficiales. Cabe señalar también que la especial incidencia de la vulnerabilidad habitacional y de los hogares en el caso de las personas mayores, sobre todo, de mujeres, se manifiesta ya en los años 70 , como consecuencia en ese momento, sobre todo, de las viudedades y del saldo migratorio negativo imperante, expresivo de la tendencia de los hijos del barrio a abandonarlo a la hora de crear su propio hogar. No obstante, en ese momento la cifra de hogares solitarios era mucho menor que en la actualidad, en un proceso que sigue profundizándose de 2001 a 2011 y que en 2018 se traduce en un $11 \%$ de hogares con una sola persona mayor de 65 años, y un el $39 \%$ de hogares unipersonales de personas entre 16 y 64 años.

Por último, conviene señalar que estas vulnerabilidades en el terreno habitacional, residencial y urbanístico resultan concomitantes con un sistema de tenencia que contrasta con el modelo imperante en otras partes de la ciudad desde mediados del siglo pasado en adelante, en la medida en que en este espacio se encuentra un importante número de viviendas en alquiler. Precisamente, esta disponibilidad constituye, como se ha señalado, uno de los factores de atracción de personas migrantes extranjeras económicas al barrio, muchas de las cuales tendrán que recurrir al hacinamiento para poder afrontar los costes crecientes de los alquileres. De otro lado, la extendida presencia del modelo llamado de "renta antigua" respaldado por la legislación anterior a la liberalizadora de finales del siglo pasado, facilita la permanencia en el barrio de personas vecinas de escasos recursos económicos, en viviendas, en muchos casos, requeridas de mejoras que ni estas personas ni sus caseros llevan a cabo.

Los datos censales dan cuenta del mayor peso en Embajadores de las viviendas que no están en buen estado, que en 2001 representaban 


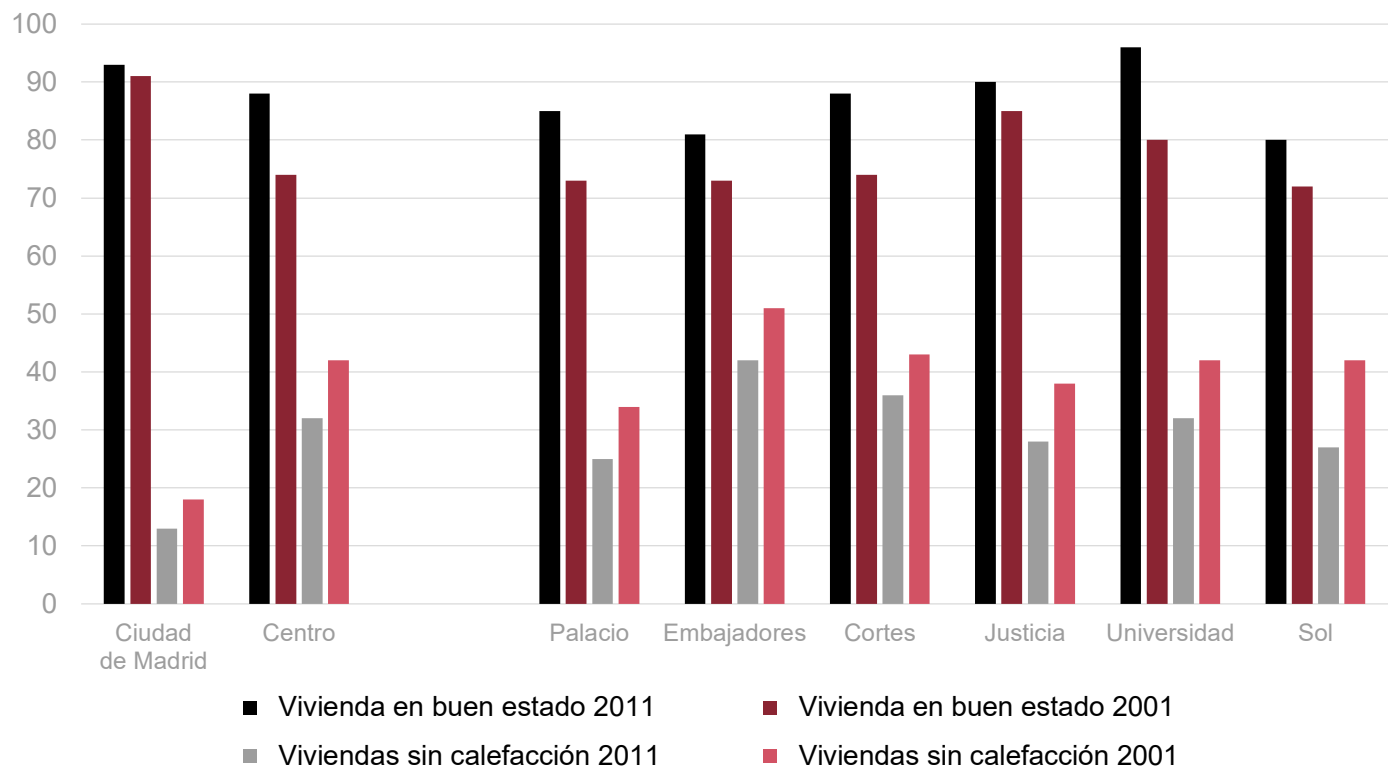

FIG. 8/ Porcentaje de viviendas en buen estado y porcentaje de viviendas sin calefacción. 2001-2011.

casi un $30 \%$ del total del alojamiento, muy por encima de lo que era el caso en el Distrito y el conjunto de Madrid. Algo semejante sucede con los datos censales relativos al total de viviendas sin calefacción. De otro lado, sin embargo, es importante destacar la mejoría que se produce en el barrio en relación con estos dos aspectos de 2001 a 2011, de manera incluso más señalada a lo que sucede en los dos ámbitos espaciales superiores considerados en la FIG. 8. Algo semejante sucede con el hacinamiento habitacional. Los datos ponen de manifiesto una reducción del número de hogares de mayor tamaño, si bien todavía los de 9 miembros siguen teniendo un peso superior al que alcanzan en otros barrios del Distrito Centro: Embajadores contaba con el 2,3\% de este tipo de hogares en el año 2011, frente al 1,7\% de la Comunidad de Madrid o al 1,4\% del distrito Centro. La aproximación expuesta, apoyada en la comparación intercensal de 2001 y 2011, así como en las otras las fuentes demográficas complementarias mencionadas, se ve ratificada por el análisis llevado a cabo de acuerdo con la metodología empleada por Temes (2014) para el municipio de Madrid con datos del Censo de Población y Viviendas de 2011, utilizando como unidad de análisis espacial las ya definidas UTAS (FIG. 9). Así por lo que hace a la vulnerabilidad sociodemográfica, la correlación, elevada y negativa ( $r=-0,738 ; 82 \%$ varianza explicada) entre, de una parte, los hogares



FIG. 9/ Análisis de las dimensiones de la vulnerabilidad. Distrito Centro, 2011.

Fuente: elaboración propia a partir de los datos del Censo de población y viviendas 2011. 
nucleares "clásicos", compuestos por una pareja y su descendencia, y de otra, los hogares de personas de más de 75 años, demuestra que ante la presencia de un colectivo se produce la ausencia del otro. En este caso, los valores arrojan una presencia importante de población de cuarta edad muy por encima de los valores del municipio de Madrid en casi todas las UTAS analizadas, en detrimento de la población con descendencia en el barrio.

Este peso notable de la población de más de 75 años, y la escasa presencia de parejas con hijas e hijos, se evidencia también en los barrios de Palacio y Cortes, pero resulta especialmente significativa en las cuatro UTAs que conforman el barrio de Embajadores/Lavapiés, concentrándose particularmente alrededor de la zona de Tirso de Molina y en el área más cercana a la zona de Argumosa-Atocha. Por lo que hace a la formación de la población y el mercado laboral, y considerando la población de 20-64 años con ESO y la tasa de paro ( $r=643 ; 87 \%$ varianza explicada) los datos del distrito Centro no resultan llamativos si se relacionan con los valores medios de la capital de España, como pueden ser el caso en barrios periféricos de la ciudad de Madrid. Dichos datos ponen de manifiesto el cambio de la población en relación a estos aspectos en el centro de la ciudad. Y ello no sólo debido a la llegada de población más joven con un mayor nivel formativo, sino también gracias a la progresiva disminución del número de personas mayores. Este aumento tanto del porcentaje de población con estudios superiores como de población que han cursado únicamente estudios primarios es perfectamente compatible con los valores que nos arroja el indicador de la dimensión "educativa/laboral" - basada en TEMES (2014) - en la medición de las diferentes aristas de la vulnerabilidad explicada anteriormente, y cuyo objetivo es compararla con los valores medios del municipio de Madrid. El contraste de los valores de las cuatro UTAS que componen el barrio de Embajadores se sitúa por debajo de la media del municipio, refiriendo una posición menos vulnerable en términos generales, pero no niega el crecimiento del nivel de estudios tanto primarios como superiores de las vecinas y vecinos del barrio.

Por lo que hace a la medición de la vulnerabilidad residencial, conformada, sobre todo, por las viviendas sin calefacción y por la población que reside en viviendas ubicadas en terceras plantas o más y no disponen de ascensor, se pone de manifiesto una correlación fuerte ( $r=646 ; 82 \%$ varianza explicada), que ratifica la apreciación de que en gran parte del barrio de Embajadores/Lavapiés hay colectivos cuyas condiciones habitacionales presentan carencias básicas. Dentro del barrio, se puede observar una mayor concentración de este colectivo que reside en condiciones desfavorables en el área definida como el Rastro, así como en la zona central, entre las calles Ribera de Curtidores y Lavapiés. Finalmente, por lo que se refiere a las personas migrantes económicas, se vuelve a evidenciar de nuevo la concentración de esta población en el área central del barrio, entorno a la arteria representada por Mesón de Paredes, en donde se aglutina un alto porcentaje de población migrante económica, muy por encima de la media del Municipio.

\section{Conclusiones: Embajadores/ Lavapiés, un espacio complejo de vulnerabilidad variable}

El análisis confirma la necesidad de tener en cuenta la multiplicidad de dinámicas que se despliegan en el barrio desde finales del siglo pasado, y especialmente, durante el periodo intercensal que transcurre entre 2001 y 2011 . No parece que las transformaciones relacionadas exclusivamente con la gentrificación, o bien con el impacto de la migración transnacional o, en fin, con el de la vulnerabilidad o la exacerbación de la vigilancia, el control y la seguridad, agoten los cambios conocidos en su suelo. Por el contrario, se pone de manifiesto la pertinencia de su consideración conjunta, y las posibles interrelaciones existentes entre estos procesos, lo que no ha estado exento de ambivalencias y hasta de paradojas. De aquí la propuesta de conceptualización de Embajadores/Lavapiés como un espacio urbano complejo, siguiendo la formulación debida a URRY (2004). Dicha complejidad se refiere, a la multidimensionalidad de las dinámicas en curso en la etapa considera$\mathrm{da}, \mathrm{y}$ a la heterogeneidad de sus resultados. Si se incorporan al barrio sectores sociales de clases medias vinculados a la gentrificación, que habitan, en un número importante, en hogares de personas de edades centrales sin descendencia, irrumpe también en estos mismos años en su suelo una población migrante extranjera económica procedente de más de ochenta nacionalidades distintas (PÉrEZ-AGote, TEJERINA \& BARAÑANO, EDS. 2010; BARAÑANO \& DOMÍNGUEZ, 2015; ROMERO, 2006 y 2007; Riesco, 2010A; García SELgAs, 2016). La formación educativa y los datos laborales de estos dos colectivos son también muy distintos, creciendo tanto los niveles educativos inferiores y superiores, dando lugar a una dualización. 
La evolución en los modelos de hogar y los aspectos habitacionales apuntan también a un aumento de la heterogeneidad, incluyendo el crecimiento de los hogares envejecidos, de los de personas solitarias de más de 75 años, así como de los integrados por un número muy elevado de personas (aunque muy minoritarios, aumentan); la disminución de los hogares compuestos por familias nucleares, constituidos por los progenitores y su descendencia; la existencia de hogares habitados exclusivamente por personas migrantes extranjeras; o la reducción de la infancia y la población más joven. Por lo que hace a la dimensión residencial, se constata que sigue existiendo un porcentaje no desdeñable de viviendas sin calefacción o de edificios en mal estado, superior al del Distrito.

Todas estas conclusiones son avaladas no sólo por el análisis cuantitativo, sino también por la investigación cualitativa llevada a cabo en los años en el período citado. Es más, esta última no solo ratifica este análisis, sino que, en muchos casos, lo refuerza, al poner de manifiesto situaciones de vulnerabilidad importantes, referidas a las condiciones habitacionales o a determinados colectivos, que han podido permanecer opacas para los datos oficiales. La heterogeneidad se manifiesta, asimismo, en la presencia que unos y otros colectivos y procesos tienen en las diferentes zonas del barrio. Los resultados expuestos evidencian que en Embajadores/ Lavapiés se mantiene una segregación espacial interna importante, que, en buena medida, sigue el patrón de la señalada en estudios anteriores (BARAÑANO \& RIESCO \& ROMERO \& GARCÍA, 2006; PÉrez-Agote, Tejerina \& Barañano, eds., 2010; RIESCO, 2010a \& 2010b). Además, las subzonas que cuentan con más personas de cuarta edad, o bien de migrantes extranjeros económicos, son también las que tienen un mayor peso de las viviendas con deficiencias.

Que Embajadores/Lavapiés sea un barrio complejo no equivale, en consecuencia, a señalar que se trate de un espacio de mezcla social. Por el contrario, parece claro que los diferentes colectivos, edificios, viviendas, y situaciones sociales que tienen sede en su suelo, lejos de ocupar espacios indiferenciados, siguen pautas de segregación interna relativamente precisas, que, en buena medida, reproducen, y hasta amplifican, las conocidas previamente. En definitiva, la complejidad de Embajadores/Lavapiés parece aproximarse más a la que caracteriza a ciertos barrios de los cascos históricos de las ciudades europeas frente a lo que suele ser el caso en algunas periferias o en otros modelos de ciudad (CASTELLS, 1997).
Esta misma diversidad se refleja, asimismo, en las representaciones simbólicas e imaginarias del mismo, entre su concepción como un barrio en proceso de gentrificación acelerada; un espacio multicultural por excelencia; un territorio sometido, antes que nada, a la vigilancia, o, en fin, como aquí se propone, su consideración como un espacio complejo, multidimensional, configurado por procesos que, siendo de muy diferente factura, coinciden por las razones expuestas en este singular territorio madrileño. Estas variadas aproximaciones conceptuales y analíticas coexisten, además, con una amplia panoplia de representaciones imaginarias, vehiculadas por los medios de comunicación, por su heterogéneo vecindario o por las múltiples personas que acuden al mismo en busca de ocio y consumo, o del compromiso con un proyecto comunitario de recrear el "barrio" desde diferentes políticas de la vida (GIDDENS, 1993).

Por último, cabe abordar una cuestión que, aun habiendo recibido sistemáticamente una respuesta negativa por parte de la literatura científica ha despertado, sin embargo, gran interés en los discursos y debates sociales. Se trata de la pregunta acerca de si cabría identificar a este barrio con algunas de las conceptualizaciones de la vulnerabilidad y la precariedad urbanas que han despertado más interés en las últimas décadas, como las de los llamados espacios de "discriminación negativa", formulada por Robert Castel respecto de los "grands ensembles" de las periferias en declive del declive industrial y de la migración económica extranjera (CASTEL, 2007: 17); los "hiperguetos" de las grandes metrópolis norteamericanas del siglo XXI (WACQUANT, 2006); o los "guetos urbanos" de la pobreza, la segregación y la violencia, definidos por LAPEYERONNIE (2008). No cabe aquí analizar este contraste en profundidad, pero sí se puede señalar que el análisis del barrio ratifica la falta de adecuación de una comparación de este tipo. Entre ellos, se identifican fenómenos como el predominio de la monoetnicidad de los grupos migrantes venidos al barrio; el declive de las actividades económicas o de la población; o el envejecimiento creciente de los espacios de declive retratados por Castel. También se han destacado la pobreza extendida, a la que se refiere Lapeyronnie; la mínima intervención pública en los "hiperguetos" que señala Wacquant; o, en fin, el hecho de que en modo alguno son espacios de consumo y ocio para transeúntes que todos los días entran y salen del barrio, todo lo cual contrasta vivamente con lo que sucede en Embajadores/Lavapiés. A ello se suma, sin duda, la ausencia en todos esos otros espacios de "relegación" (CASTEL, 2007) de una gentrificación 
que ni se espera ni se ha producido aún. Es cierto que el reconocimiento de estas realidades no debe conducir a olvidar el peso que siguen teniendo en su suelo muy distintas vulnerabilidades, que persisten, se refuerzan o incluso se configuran de nuevo en el período analizado. De ahí la apuesta de estas páginas en favor de la comprensión de Embajadores/Lavapiés como un espacio social complejo, atravesado por procesos, colectivos y representaciones muy heterogéneas, muy expresivas de las cambiantes sociedades de nuestro incierto mundo actual (WALleRstein, 2002).

\section{Bibliografía}

Alguacil, J. (2006): "Barrios desfavorecidos: un diagnóstico de la situación española", en V Informe FUHEM de políticas sociales: La exclusión social y el estado del bienestar en España, Madrid: FUHEM-Icaria, 155-168.

- \& CAmacho, J. \& HeRnández, A. (2013): La vulnerabilidad urbana en España. Identificación y evolución de los barrios vulnerables. Empiria. Revista de Metodología de Ciencias Sociales, $0(27), 73$.

Álvarez-Benavides, A. (2009): Cruce de caminos: tiempos, espacios e identidades que se transforman. El caso del barrio de Lavapiés en Madrid, en MONTORO, C. \& LÓPEZ, D \& PONS, J.J. \& BARCENILLA: La inmigración internacional: motor de cambios sociodemográficos y territoriales, EUNSA.

- (2010): Femmes marocaines à Lavapiés (Madrid). La visibilité et invisibilité dans un espace global et local, NAQD - n²8: 201-2012.

ANTON-Alonso, F \& al. (2017): Innovació social i política, densitat institucional i vulnerabilitat urbana a la Barcelona metropolitana. Recuperado el 1 de julio de 2020 de

https://iermb.uab.cat/ca/iermb/estudi/densitatinstitucional-barris-i-el-seu-rol-en-els-processos-devulnerabilitat-urbana-innovacio-imetropoli-2a-fase/

AnTON-Alonso, F, \& PoRCEL, S. (2018): La vulnerabilitat urbana a la Barcelona metropolitana: la dinàmica de la persistència. In: R. GomÀ (Ed.), Anuari Metropolità de Barcelona: El dret a la metròpoli (pp. 23-47). Bellaterra: Institut d'Estudis Regionals i Metropolitans de Barcelona.

BARAÑANO, M. (2010): "Convergencias y divergencias de dos barrios en transformación", en A. PÉrez-Agote \& B. TeJerina \& M. BARAÑANo (Eds.): Barrios multiculturales. Relaciones interétnicas en los barrios de San Francisco (Bilbao) y Embajadores/ Lavapiés (Madrid). Madrid: Trotta, 283-340.

— \& al. (2006): Globalización, inmigración transnacional y reestructuración de la región metropolitana de Madrid. Estudio del barrio de Embajadores de Madrid. Madrid, FSI. Primer Premio a la Investigación del FSI en su convocatoria de 2006.

— \& DomínguEZ, M. (2015): Barrios multiculturales. Relaciones interétnicas en el barrio de Embajadores/
Lavapiés (Madrid). Congreso Migraciones Contemporáneas, Territorio y Urbanismo, Universidad Politécnica de Cartagena, 9 y 10 de julio, ponencia invitada.

CASTEL, R. (2007): La discrimination négative. Citoyens ou indigènes?. Paris, Seuil.

CASTELLS, M. (1986): La ciudad y las masas, Madrid, Siglo XXI.

- (1997): La sociedad red, volumen I: La era de la información. Economía, sociedad y cultura. Madrid, Alianza.

Della Porta, D. \& Keating, M. eds. (2013): Enfoques y metodologías de las ciencias sociales. Una perspectiva pluralista. Madrid, Akai.

DomingueZ, M. \& SoRANDO, D. \& UCEDA, P. (en curso): Los cambios de la vulnerabilidad socio-residencial en Madrid (2001-2011). Revista Papers. N. 63. Entregado para su publicación "

EseVERRI, C. (2017): "A Spanish Ghetto? The effect of Intermediary Structures on the Second Generation of Immigrants' Integration", Migraciones Internacionales, volumen 9, n. $^{\circ} 2$, julio-diciembre.

FERnANDEZ-GARciA, M. \& al. (2018): El Análisis de la Desigualdad Urbana Propuesta y validación de un índice de nivel socioeconómico en áreas urbanas españolas (1991-2001). Empiria. Revista de Metodología de Ciencias Sociales, 39, pp. 49-77.

GARcíA PÉREZ, E. \& SEQUERA, J. (2013): Gentrificación en centros urbanos: Aproximación comparada a las dinámicas de Madrid y Buenos Aires. Quid16, Volumen 16, n. ${ }^{\circ}$ 3: 44-61.

GaRcía Selgas, F. (2016): "Redoing Gender Relations in Transnational Lives: Ecuadorian and Senegalese Migrants in Spain". Men and Masculinities 19(5): 439- 459.

DOI http://dx.doi.org/10.1177/1097184X15597965

GIDDENS, A. (1993): Consecuencias de la modernidad. Madrid, Alianza.

GimÉnEz Romero, C. (2000): "Inmigración y multiculturalidad en Lavapiés", en Universidad Pontificia de Comillas e Instituto Universitario Ortega y Gasset (2000), I/ Congreso sobre inmigración en España. España y las migraciones internacionales en el cambio de siglo, Universidad Pontificia de Comillas e Instituto Universitario Ortega y Gasset.

Hernández AJA, A. (2007): Áreas vulnerables en el centro de Madrid. Cuadernos de Investigación Urbanística, 53, 5-97.

LAYPERONIE, D. (2008): Ghetto urbain. Ségrégation, violence et pauvreté dans la France d'aujourd'hui, Paris: Robert Laffont.

LEAL, J. \& MAYEUR, C. (1998): Vivienda e integración social de los Inmigrantes, Madrid, Ministerio de Trabajo y Asuntos Sociales.

LEAL, J. \& ALGUACIL, A. (2012): "Las condiciones y el comportamiento residencial de los inmigrantes en España" en Eliseo AJA FERnÁNDEZ \& al. (ed) $\underline{\mathrm{La}}$ hora de la integración/Madrid. Observatorio de la inmigración págs. 126-157.

LeAL, J. \& SoRANDO, D. (2016): "Economic Crisis, Social Change and Segregation Processes in Madrid". In: TAMmARU, T. \& al. (eds.). SocioEconomic Segregation in European Capital Cities. London: Routledge. 
LEFEBVRE, H. (2013): La producción del espacio. Madrid: Capitán Swing.

LORA-TAMAYO D' OcóN, G. (2007): Inmigración extranjera en la Comunidad de Madrid Informe 2006-2007, Madrid: Delegación Diocesana de Migraciones (ASTI)"

MARTínEZ, A. \& LEAL, J. (2008): "La segregación residencial, un indicador espacial confuso en la representación de la problemática residencial de los inmigrantes económicos: el caso de la Comunidad de Madrid". ACE: Architecture, City and Environment, N. ${ }^{\circ} 8$.

Mendez, R. \& Abad, D. \& Echaves, C. (2015): Atlas de la crisis: Impactos socioeconómicos y territorios vulnerables en España. Valencia: Tirant lo Blanch.

Pérez-Agote, A. \& Tejerina, B. \& Barañano, M. eds. (2010): Barrios multiculturales. Relaciones interétnicas en los barrios de San Francisco (Bilbao) y Embajadores/Lavapiés (Madrid). Madrid, Trotta.

RAGIN, C. C. (2014): The comparative method: Moving beyond qualitative and quantitative strategies. Univ of California Press.

REQUenA, M. \& SÁNCHEZ-DomíngUeZ, M. (2011): “Las familias inmigrantes en España", Revista Internacional de Sociología, número monográfico n. ${ }^{\circ} 1$, 79-104.

RIESCO SANZ, A. (2010a): Inmigración y trabajo por cuenta propia. "Economías inmigrantes" en Lavapiés (Madrid), tesis doctoral, UCM, Madrid.

- (2010b): "Inmigración y economías étnicas", en Pérez-Agote, A. \& Tejerina, B. \& Barañano, M. eds. (2010): Barrios multiculturales. Relaciones interétnicas en los barrios de San Francisco (Bilbao) y Embajadores/Lavapiés (Madrid). Madrid, Trotta: 265-278.

ROMERo BACHILLER, C. (2003): Los desplazamientos de la "raza". De una invención política y la materialidad de sus efectos» [Displacements of "Race". On a Political Invention and the Materiality of its Effects], Política y Sociedad 40(1). (pp.111-128) ISSN: 1130-8001.

- (2006): Articulaciones identitarias: prácticas y representaciones de género y "raza"/etnicidad en "mujeres inmigrantes" en el barrio de Embajadores (Madrid), Tesis doctoral. Director: Fernando J. García Selgas. Presentada el 20/12/2006. Dpto. Sociología v (Teoría Sociológica). Fac. CC. Políticas y Sociología, UCM.

- (2007): "El exotismo de los cuerpos y la fetichización de la mirada en la producción de las «mujeres inmigrantes» como "otras»" [Bodies Exotism and Gaze Fetishisation in the Production of "Immigrant Women" as "Others"], in María José SÁNCHEZ LEYVA \& Alicia ReIgada (eds.) Crítica Feminista y
Comunicación (pp. 186-214), Sevilla: Comunicación Social, 2007. ISBN: 84-96082-39-3.

- (2010). "Embajadores/Lavapiés: Desplegando el escenario", en PÉrez-Agote, A. \& TEJERINA, B. \& BARAÑANO, M. eds. (2010): Barrios multiculturales. Relaciones interétnicas en los barrios de San Francisco (Bilbao) y Embajadores/Lavapiés (Madrid). Madrid, Trotta: 131-162.

RuIZ CHASCO, S. (2020): Cuando desigualdad produce (in)seguridad: una aproximación comparada a dos barrios madrileños. Revista Crítica Penal y Poder 2020, n. ${ }^{\circ}$ 19, marzo-abril:131-156.

SASSEN, S. (2013): Expulsiones. Brutalidad y complejidad en la economía global. Buenos Aires, Katz.

SEQUERA, J. (2013): "Las políticas de gentrificación en la ciudad neoliberal. Nuevas clases medias, producción cultural y gestión del espacio público. El caso de Lavapiés en el centro histórico de Madrid". UCM. Facultad de Ciencias Políticas y Sociología. Tesis Doctoral, 2013. Madrid.

— \& JANOSCHKA, M. (2015): "Gentrification dispositifs in the historic centre of Madrid: a reconsideration of urban governmentality and state-led urban reconfiguration" in LEES, L., BANG SHIN, H., \& LóPEZ-MORALES, E. (eds.), Global Gentrifications. Uneven development and displacement, Bristol, Policy Press: 375-393.

SoJA, E. (1996): Thirdspace, Cambridge, Blackwell.

SORANDO, D. \& LEAL, J. (2019): "Distantes y desiguales: el declive de la mezcla social en Barcelona y Madrid", Revista Española de Investigaciones Sociológicas, N. ${ }^{\circ} 167$, julio-septiembre, pp. 125-148.

TEMES, R. (2014): Valoración de la vulnerabilidad integral en las áreas residenciales de Madrid. EURE (Santiago), 40(119), 119-149.

TISSOT, S (2013): “¿Existe algo como un "problema de los barrios sensibles"? Retorno sobre una categoría de acción pública", Revista de Antropología Social: 22: 137-153.

UCEDA, P. (2016): La ciudad desequilibrada. El derecho a la ciudad en los barrios vulnerables de Madrid. Tesis doctoral. Universidad Complutense de Madrid.

— \& SORANDO, D. \& LEAL, J. (2018): "Citizens against urban decline: the interaction between social movements and public policies in Madrid's housing estates", en Hess, D., Tammaru, T. y van Ham, M. (eds.): Housing Estates in Europe: Poverty, Ethnic Segregation and Policy Challenges. Springer Open: 241-262.

WALLERSTEIN, I. (2002): Un mundo incierto. Buenos Aires: Libros del Zorzal.

WACQUANT, L. (2000): Parias urbanos: marginalidad en la ciudad. Buenos aires: Manantial. 